\title{
Subjective Aspects of Burnout Syndrome in the Medical Profession
}

\author{
José Manuel García-Arroyo*, María Luisa Domínguez-López \\ Department of Psychiatry, Faculty of Medicine, University of Seville, Seville, Spain \\ Email: [imgarroyo@us.es
}

Received 17 September 2014; revised 15 October 2014; accepted 8 November 2014

Copyright (C) 2014 by authors and Scientific Research Publishing Inc.

This work is licensed under the Creative Commons Attribution International License (CC BY). http://creativecommons.org/licenses/by/4.0/

(c) (i) Open Access

\begin{abstract}
Burnout is a syndrome related to work over load and associated, generally, with the helping professions. Here we will study it in relation to the medical profession, considering the doctor's personal aspects. For this purpose, we start with a group of physicians treated psychotherapeutically for suffering from burnout. The method is qualitative and consists of recording as accurately as possible the verbal expressions of the patients. Since there was plenty of verbal material waste, we had to differentiate between "useful statements" (type I) and "useless" (type II), whose characteristics we defined exactly. As a result we find that these professionals show emotional mismanagement due to lack of subjective recognition of affective experiences. This causes an overflow that physically manifests itself in the absence of any mental processing, resulting eventually in the triad features of the syndrome. Subjectively, we find the origin of this in the "medical ideals" that hinder these professionals from recognizing the above mentioned experiences since they consider them as inadequate for the performance of their work and contravene their values. At the same time, these subjects were busy helping others, but were unable to help themselves or ask for help.
\end{abstract}

\section{Keywords}

Burnout Syndrome, Doctor Health, Emotions, Emotional Management, Subjectivity, Burnout

\section{Introduction}

The physical and mental health of medical practitioners is a concern in these times, due to the working conditions in which this profession functions. In fact, the rates of morbid-mortality from vascular disease, cirrhosis of the liver and traffic accidents are three times higher in physicians than in the general population (Marmor, 1953; Vaillant, Sobowale, \& McArthur, 1972; Vaillant, 1977; Krakowski, 1982). To this we should add the psycho-

*Corresponding author. 
pathological manifestations that appear in greater proportion than in other professionals at the same social status, such as: alcoholism, abuse of drugs or pharmaceuticals, changes in eating habits, marital conflicts, gambling, depression, etc. (Vaillant, Sobowale, \& McArthur, 1972).

This is because belonging to this profession brings much satisfaction, but it also gives rise to problems and tensions due to the complexity of how it functions and, in this sense, it is one of the most problematic occupations with respect to stress and its effects (Cartwrigt, 1979).

Hence burnout or "syndrome of professional burnout" is common in the field of medicine and it will be the subject of this paper. This is referred as a set of clinical manifestations described in 1974 by Freudenberger, who observed that most of the volunteers who worked at a New York clinic for addicts, about one year after starting work there, experienced exhaustion and loss of motivation for work, which was accompanied by symptoms of depression and anxiety (Freudenberger, 1974). Shortly afterwards, Maslach described the affected as suffering from "emotional overload" and popularized the term burnout, a term which was not stigmatizing to those who were suffering from this syndrome. She defined the triad characteristic of the syndrome, namely: emotional exhaustion, depersonalization and diminished sense of personal accomplishment (Maslach \& Jackson, 1981). From now on we will use interchangeably the expression burnout syndrome or its abbreviation (BS) (Vega \& Pérez Urdaniz, 1998).

To Maslach this was a disorder associated with the helping professions, that is, those offering direct human services, which obviously include health professionals. Doctors, as members of this group, have a high risk of burnout; in fact, it is estimated that between $10 \%$ and $20 \%$ of them are emotionally disturbed (Mingote Adán \& Pérez Corral, 1999).

As we understand it, individuals suffering from BS fail to adapt due to exhaustion and the depletion of psychological resources needed to cope with the demands that require working with people, causing an imbalance between excessive work demands and limited coping resources (Mingote Adán, \& Pérez Corral, 1999). This is considered to be the final stage of a progression of unsuccessful attempts to manage chronic stress (Moreno et al., 1990). In fact a series of steps involving attempts at adaptation have been described (Cherniss, 1980; Edewich \& Brodsky, 1980). At the end of the process, it is common to find a set of typical alterations: detachment from work, depersonalization, insensitivity to the people being helped, lack of empathy, etc. We have seen that family doctors, general internists and emergency physicians have a higher risk of suffering from this disorder.

Notwithstanding what has been said above, the cause of the suffering is not limited to external conditions (huge volumes of patients, the need to make critical decisions, the pressure of not making mistakes, etc.), but also to other aspects that are intrinsic to the personality of who is suffering from it. Therefore, the aim of this article is to study the subjective components of the doctors suffering from BS; to achieve this, we must clearly limit ourselves to the psychological side, disregarding the biological aspects (increased cortisol level, elevated BP, etc). Doing this is fully justified, since the psychological factors are fundamental in the psychotherapy of these people and, therefore, we should know them as profoundly as possible.

\section{Material and Method}

We start with a group of doctors who have observed their own symptoms of burnout syndrome (12 in total, between 30 and 51 years of age) and who were treated with formal psychotherapy sessions. Of these, only four cases are presented for a concise dissertation, bearing in mind that the results would be the same had we also considered the other cases because their verbal articulations were very similar. The cases presented are:

P-1. Male, 35 years old. Surgeon. Works in a hospital unit. Smoking and consumption of benzodiazepines. On sick leave.

P-2. Male, 48 years old. Internist. Works in a hospital emergency service. Consumption of benzodiazepines and marital conflicts.

P-3. Female, 45 years old. Family doctor. Works at a health centre in the province. Excessive food intake with weight gain.

P-4. Male, 51 years old. Family doctor. Occasionally working in the emergency department of a health centre. Excessive alcohol consumption.

The method is qualitative and consists of conducting weekly interviews in which verbal articulations are faithfully recorded. It is assumed that these are isomorphic to the inner experiences referred to the state they present and their feelings at the time. To achieve an accurate record of their remarks, we must follow a series of 
methodological rules during the interviews:

1) Take a careful attitude to what the patient expresses, leaving aside any ideas that can interfere with the uptake of the discourse (theories, authors, concerns, memories, occupations, etc.). Elsewhere we have called this methodological attitude "decontaminant" because it allows us to record spontaneous material free from influences of the observer (García Arroyo \& Domínguez López, 2010).

2) The experience studied is complex, that is to say, it is made up of numerous psychological components, hence the need to decompose it into its various elements (analysis). This is seen in the statements we obtain, where each reveals a particular facet of the problem.

3) Many statements are obtained during the interviews and those used in the research capture the emotional aspects of the experiences and are not usually expressed outside the consultation room for various reasons (embarrassment, fear of criticism, loss of face, etc). This is why they have been categorised as "useful" (type I) and “useless” (type II) statements (García Arroyo \& Domínguez López, 2010), whose characteristics are reported in Figure 1. Given that this is not a forced confession and the patients are not prompted, the interviewer has to be patient for the expressions of the problem studied to emerge without any pressure.

4) As we move forward in the interviews, the patients are enriched with new verbal material and we observe how they analyse themselves in finer detail. This is because language has the particularity to depict experiences and in doing so, it provides them with clarity and structure (García Arroyo \& Domínguez López, 2010). Obviously, the new verbal material has not been induced by the observer.

Note that we have not spoken of using quantitative methods (scales, questionnaires, tests, ...) and the reasons are obvious to us: a) when presented with a questionnaire or test, the patient is forced to focus on it and we fail to obtain the verbal elements that describe his difficulties, while acting as a distraction from the purpose of the research b) subjective analyses, as we have demonstrated in other studies, do not have a numeric value, that is to say, they are not quantitative but qualitative in nature (García Arroyo, 2001a, 2001b, 2007).

A qualitative method attempts to answer "why", or "how", rather than "how often", or "how much" (Taylor \& Bogdan, 1992; Buston, Parry-Jones, Livingstone, Bogan, \& Wood, 1998), but to proceed qualitatively does not imply that the results lose their accuracy (Alonso Fernández, 1989). To add one last remark about the method: while quantitative studies use numbers and statistics, qualitative studies use concepts (Munarriz, 2004). Some of these methods, previously used or newly created, according to the requirements of the study, can generate an unexpected understanding of the subject under study. In this sense, it is now absolutely necessary to ascertain

\begin{tabular}{|ll|}
\hline $\begin{array}{l}\text { Useful statements } \\
\text { (type I) }\end{array}$ & $\begin{array}{l}\text { Useless Statements } \\
\text { (type II) }\end{array}$ \\
The least frequent & The most frequent \\
$\begin{array}{l}\text { The most important } \\
\text { for the investigation }\end{array}$ & The least important \\
$\begin{array}{l}\text { Appear surprisingly and } \\
\text { spontaneously to the } \\
\text { patient and investigator }\end{array}$ & $\begin{array}{l}\text { Appear often } \\
\text { directed or voluntarily. }\end{array}$ \\
$\begin{array}{l}\text { They may be accompanied } \\
\text { emotional expressions. }\end{array}$ & $\begin{array}{l}\text { Not often accompanied by } \\
\text { emotional expressions }\end{array}$ \\
$\begin{array}{l}\text { Only appear in the } \\
\text { professional context }\end{array}$ & $\begin{array}{l}\text { Also appear outside the } \\
\text { professional context }\end{array}$ \\
$\begin{array}{l}\text { They are entirely } \\
\text { original }\end{array}$ & $\begin{array}{l}\text { These are phrases read } \\
\text { or heard before. }\end{array}$ \\
$\begin{array}{l}\text { They express the } \\
\text { subjective experience }\end{array}$ & $\begin{array}{l}\text { They show learned and } \\
\text { repeated speech }\end{array}$ \\
\hline
\end{tabular}

Figure 1. Differences between type I and type II statements. 
the distinction between "emotions" and "feelings" (see Figure 2) from the material being studied, a distinction that proves to be clarifying, since the expressions of the patients and many texts (Mingote Adán \& Pérez Corral, 1999; Rodríguez Marín, 2001) refer to emotions, in the case of the burnout syndrome. However, a qualitative study is not content just to use the appropriate concepts, but it needs to provide them with some sense and try to make them useful in understanding the phenomena being treated and to draw new conclusions about what has been achieved previously.

\section{Results}

We will now analyze the most relevant aspects involved in the development of burnout but, as we now know, the external aspects have been left out to focus on the experiences of the patient.

\subsection{Inadequate Emotional Management}

Emotions are the source of the burnout syndrome and are triggered by setbacks at work. The responses of the physicians show all the characteristics of the emotions referred to in Figure 2. (P-1: "Now I see that I have taken everything very badly, my body responded to everything that happened to me, but I didn't realize it. It was too intense for me!"; P-2: "There were times when I was enraged, but I had to keep my mouth shut and carry on, what could I do?"; P-3: "I can't describe what happened at the time, I'm calmer now... but I think that at work I was going up and down like a Ferris wheel").

Characteristically, the doctors do not recognize their emotions, and so they lose the ability to manage them. (P-1: "I did not realize what was happening, I just kept on working."; P-3: "I didn't know what was happening to me, it was like going over a waterfall, by the time I noticed it, it was too late"; P-4: "I didn't know how to put my life in order, nor make any sense of it").

This is because doctors have a great deal of difficulty in admitting that they are disturbed, and they do not recognize that they are angry, tense, at the end of their tether, or distressed, since they consider these traits as improper attributes in the medical profession. They try to behave as if they were in control of situations all the time by maintaining an impeccable façade (P-1: "I think that feeling affected by what happens to one is not

\begin{tabular}{|lll|}
\hline Intensity & $\begin{array}{l}\text { Emotions } \\
\text { Raised }\end{array}$ & $\begin{array}{l}\text { Feelings } \\
\text { Infrequent }\end{array}$ \\
$\begin{array}{l}\text { Starting and } \\
\text { stopping }\end{array}$ & Short & Long \\
$\begin{array}{l}\text { Somatic } \\
\text { manifestations }\end{array}$ & Abundant & Scarce \\
$\begin{array}{l}\text { Rational } \\
\text { thinking }\end{array}$ & Dissolution & Maintained \\
$\begin{array}{l}\text { General } \\
\text { functioning }\end{array}$ & Defensive & $\begin{array}{l}\text { Connected or } \\
\text { relational }\end{array}$ \\
$\begin{array}{l}\text { Psychological } \\
\text { construction }\end{array}$ & None & Progressive \\
$\begin{array}{l}\text { Effects on the } \\
\text { personality }\end{array}$ & Destabilizing & Stabilizing \\
\hline
\end{tabular}

Figure 2. Differences between emotions and feelings. 
proper for a doctor, because we have to be strong"; P-2: "The truth is that one cannot crumple due to the nonsense that happens every day at work. A doctor is always a doctor". P-4: "The idea of walking around whining or blubbering in a corner is abhorrent and I don't think it's the behaviour of a doctor").

From these statements we conclude the following: 1) That they confuse the "internal" with the "external". To feel the effect of an emotion subjectively does not mean they have to express it (e.g.: if you feel sad, you don't have to cry; if you are angry, you don't have to scream); 2) They cannot bear thinking of what they can be feeling since any term that defines an emotion (wrath, dread, anger, burden, ...) contravenes the "ideals" of the medical profession (to be strong, to respond forcefully, to solve problems, etc.) and 3) If they are unable to name emotions, they cannot be aware of them, and consequently, they cannot manage them adequately.

The above becomes complicated when we consider that these people are immersed in situations that trigger emotions and besides, they cannot break away psychologically. This means they do not disconnect from work because they carry on with the image of the events that occurred during the day, producing continuous repetitions that prevent relaxation, rest or even sleep (P-1: "I've wanted to free my mind from the upheaval at the hospital, but I've failed and I could not sleep because what had happened during the day kept coming back to my mind". P-2: "I haven't been able to get away from my work at all, unfortunately I took the setbacks from work home with me". P-3: "It was easier to stick a knife in a loaf of bread and cut it than to do the same with my work. Disconnect, me? Impossible!" P-4: "To leave work behind, relax and move on to do other things is fine in theory, but in reality I just can't do it").

These professionals function as if they were still at work, even when resting. In other words, a change of scenery does not imply a change of mind. Resting does not neutralize tensions just because it ceases to exist.

\subsection{Overflow}

Continued incompetent emotional management leads to a state of nervous tension which is manifested in all the subjects studied (P-1: "Between one thing and another, I found myself suffocating. I would say I haven't had any rest. Now I find myself anguished", P-3: "I've seen myself as never before: too overloaded". P-4: "I have been unable to relax and that has caused a significant impact on me during this time... I don't wish this on anyone".

Consequently, we can detect the exhaustion that has resulted from the inner struggle between maintaining the inevitable (unprocessed) emotions and the effort of keeping up the pretence of being a complicated professional performer (P-1: “I'm too tired to solve problems, I can't do it now... Now I can see it more clearly: I have been fighting against too many setbacks for nothing". P-4: "At first, I had a lot of energy for consultations, but that was then. Perhaps it was my golden era?").

No wonder there were complaints and protests (P-1: "They should kill more than one person that I know, who has organized this racket. They do not think about anyone else. All they do is get medals at the expense of those working below them"), irritability, (P-2: "At home they are frightened of me because they know that I jump at them easily. It's like I no longer put up with anything. I wasn't like that'), and loss of tolerance in their professional practice"). (P-3: "I used to listen to my patients and treated them kindly, now everything has changed. Shortly after starting to talk to one, I wish he would leave as soon as possible").

This state has appeared unexpectedly, although it has had a long while to incubate (P-1: "I had to ask for sick leave, because suddenly I was in a terrible state, everything was too hard". P-3: "I have gone to work more or less dutifully during this time, but for the last few weeks I haven't been able to. It's as if my batteries had gone flat". P-4: “I don't know what is happening to me, I honestly don't know, because these last few months I have been well"). The late appearance of the burnout symptoms can be explained by the inability of the doctor to become aware of what has been happening to him; this culmination has been noted by many authors, and so Dublin and Spiegelman (Dublin \& Spiegelman, 1947) explained that doctors, who are devoted to protecting the health of others, tends to fail to protect their own health, and Alonso (Alonso Fernández, 1989) has stated that the doctor does not normally use his medical knowledge to take care of himself or self-diagnose, nor use his professional relationships to get the appropriate help he needs.

This underutilization of knowledge, people and medical centres together with the lack of self-protection, is associated with the fact that the physician helps others, but rarely seeks help or does it only when he has no choice (P-1: “Coming here has been an enormous effort and I still can't believe that I'm talking to you”. P-3: "A person like me, dedicated to caring, how is he going to ask another doctor for assistance? It is unthinkable! P-4: "Understand that coming here is very difficult for me"). 
Since there is a stagnation of the mental processes, the doctor is incapable of giving effective responses, which are products of mental elaboration. Thus, they cannot draw on their capabilities and their own resources. (P-1: "I have tried to get over it, but this has been stronger than me, which has made it worse for me". P-3: "I have always fought against everything, I have been told to be a superwoman, but now I see myself completely burnt out". P-4: "I often wonder, how did I get here? I would like to respond, but I don't have an answer at the moment... Being dead at work has caused me so much distress").

\subsection{Behavioural Automatism}

We find that these people live their professional lives mechanically, without any direct involvement in their actions (P-1: "Now I'm on sick leave as you know, but when I was working in the hospital I did things like a robot. I was programmed". P-2: "I feel like I wasn't living in the real world, as if I didn't participate in it. It is very strange". P-3: "It's like nothing mattered to me. People talk to me and I have my head in the clouds").

This phenomenon can be considered as a detachment from real life situations which Maslach (Maslach \& Jakson, 1981) spoke of as "depersonalization". The application of this psychopathological term is correct, as it has been described as an "experience of strangeness", or of "acting mechanically" and has been identified as an isolated experience in states of exhaustion, that is to say, it is not recurrent, but it can happen during panic attacks (Rojo Sierra, 1980). Acting "robotically" or "mechanically" is connected to the overflow they are suffering.

\subsection{Guilt}

The burnout syndrome provokes that the responsibility for the doctor's state falls outside (the institution, patients, the directors...) or himself. The analysis we conduct reveals that self-blame is ever present and usually takes the form of self-reproach referred to as vocational or personal incapacity, as reflected in these statements. (P-1: "My feeling is that of being completely useless, for failing to live up to the task". P-2: "I'm not happy with my actions, having put my foot in it, I feel so bad". P-3: "If I could go back, I would act differently. I haven't been intelligent, that is clear". P-4: "I don't know, but I see what has happened to me as my disability").

This feeling usually occurs secondarily, when the clinical profile has been established, and is caused by a strong tendency to underestimate the influence of the situation in which they are living, together with an overestimation of their own capabilities. This leads to the expression of omnipotence, where the doctor feels responsible for everything that happens in his professional life. He comes to recognize it (after a while), while being treated. (P-1: "I've always been far too arrogant, I admit it". P-3: "I believed I was superwoman, that I could cope with work, the children, my husband, the housework, the family..., I thought I could cope with anything").

\subsection{High Aspirations}

It should be stressed that the physicians treated shared as a common feature very high, even unrealistic expectations, in relation to their professional performances. This generates a discrepancy between expectations and the reality in their working lives. (P-1: "After talking here for a while, I can say that I have expected too much from my career, I've wanted to cure everyone and that's impossible... I'm ashamed to admit it". P-2: "I would like to say that I have been deeply disappointed with my performances and that's because I wanted to go further than I could". P-3: "It has always been typical of me to want to do more and more and go beyond my reach. That is what has left me in this state").

Consequently, there are frequent feelings of dissatisfaction, frustration and failure of which they become conscious, only during the psychotherapeutic process. Self-esteem also suffers because that on which their own image (the doctor's work) leaned, has crumbled. The self-reproaches follow on from the punishment for the inability to meet those high expectations.

Finally, we have seen how the personality traits of these people always come into play in their work performances, producing an aggregate effect between their circumstances in which they live and their personal characteristics. We have the following examples where this is observed: to make important decisions together with personal insecurity, to obtain important results along with being too self-demanding, a competitive person in a competitive environment, to be afraid of being evaluated or enduring scrutiny by superiors, etc.). Obviously, these clashes between personality and the work environment will give rise to emotions, which will complicate their clinical profile further. 


\section{Discussion}

The BS, which was initially described by the Americans with the term burnout, has been associated with the professionals who provide assistance to others; the physician, as representative of this group, is often the victim of this disorder, which is on the rise. The purpose of this article has been to demonstrate the presence of the physician's subjectivity in the development of the syndrome, beyond mere theoretical concepts, where no affected people can be found.

The consultation is the perfect setting for those affected to openly express and explain their reasons, away from the criticism of others. Therefore, starting with a group of doctors who suffer from BS, we proposed studying the subjective components that lead to burnout. The method used is to record as precisely as possible those propositions that highlight their "inner world". It is evident that there exists an isomorphism between these two elements (verbalization/subjectivity), since the respondents confirmed the veracity of the expressed sentences, especially those that were original themselves, many of which turned up surprisingly (statements "type I").

The absence of measurements has been the keynote of this work, not simply because the "inner space" has no dimensions, but any measurement would be purely contrived (García Arroyo, 2001a, 2001b, 2007). Even doctors being treated have recognized the impossibility of quantifying their emotions, feelings and attitudes.

As a result, we have found that the professionals we studied manage their emotions inadequately because: a) in the health care environment emotions are easily triggered, b) the impossibility of disconnecting from work, meaning that the triggers continue to function, c) they do not recognize the emotional reactions as such because these responses do not fit in with "the medical ideals", d) as they cannot elaborate on the emotions, stress levels increase steadily, e) this continued effect ends up draining the doctor, leading to various side effects (marital or family conflicts) and the attempts to combat the tension generated become pathological (eating excessively, alcohol consumption, drug abuse, ...) and f) all this results in the development of automatic behaviours that give rise to failures in the performance of routine tasks. It is interesting to see how this produces a drop in the resources available to neutralize the emotions, which we call "symbolic reserve"; this implies the impossibility to correctly analyze the emotions and neutralize them by representation.

The personality of the doctor is involved in the phenomena described and accordingly, we find that the respondents have high expectations that can provoke a gap between what is desired and the reality of their professional performances. This is consistent with what Maslach said of inadequate self and heteroimposed demands difficult to satisfy (Maslach \& Jackson, 1981; Maslach, 1979; Maslach \& Jackson, 1982). We are now able to offer an approximate formula for the “doctor's satisfaction” (S) that results from the difference between "executed behaviours" (Exc) and the “expected behaviors” (Exp):

$$
\mathrm{S}=\mathrm{Exc}-\operatorname{Exp}
$$

If the result of this equation is negative, it is because what is expected is higher than what is executed (Exp $>$ Exc), or because the latter is lower than expected (Exc < Exp), two conditions that follow from what has been said before. It results in greater dissatisfaction and greater probability for burnout. One limitation to the formula: it is not quantitative, but qualitative, because it is handled using the "binary code” proper of subjectivity (García Arroyo, 2004).

Job performance failure, resulting from strong pressure, leads to feelings of lack of self-esteem and guilt. The former are related to the fall of the "ideals", on account of the loss of self-worth by what they see as continuing failures. As for guilt, it arises from the impression of being responsible for everything that happens. As we see, the "I" of the physician turns out to be the centre of the devaluations and the self-reproaches, owing to an exaggerated devotion to work in order to get a good opinion of themselves, something already noted by Freudenberger (Freudenberger, 1974).

It is paradoxical to see how the personality features prone to burnout are those that form part of the "ideals" of a "good doctor", such as: perfectionism, altruism, devotion, responsibility, commitment, respect, honor, integrity, excellence, duty, service, etc. These were the same characteristics that the American Board of Internal Medicine defined as “values of the medical profession”, in 1994 (Mingote Adán \& Pérez Corral, 1999).

\section{Conclusion}

In conclusion, we will say that psychotherapy is an effective means for the treatment of these professionals, to whom we could literally apply the Latin word tripalium, (from where Spanish gets the word "trabajo”, meaning 
"work") to their "work". The word has its roots in an "ancient instrument of torture used on the untrustworthy slaves". The utility of psychotherapy has been demonstrated in all the cases studied, since this technique tries to provide patients with more resources to manage their emotions, the crux of the matter. Curiously, the doctors proved to be very bad patients, as they showed great difficulty in seeking help while prodigiously helping others, bearing the development of the insidious psychic tensions for a long time. This was seen in their great effort to seek psychotherapeutic help and keep the assistance to the sessions. Dowling described the triple sign as: ignorance, indifference and the physicians' lack of attention to their health (King, 1970).

Psychotherapy can also free the medical practitioner from his high pretensions and sideline the furor curandis mentality that causes so much damage to this profession. Instead, cultivating a good bedside manner with the patient, which Freud called "neutrality", is fundamental. Clearly, any excess is bad counsel for the doctor, because it leads to "emotional exhaustion" according to Maslach (Maslach \& Jackson, 1981). However, limits (in terms of quality, quantity and time) are admirable guidelines in these times. This is precisely what taking care of oneself means, something that the doctors treated by us do not do. Accordingly, these professionals should heed the epitaph found on the tomb of an Athenian physician in the second century BC: "These are the duties of a doctor: firstly... heal his mind and help himself before helping anyone else”.

\section{References}

Alonso Fernández, F. (1989). Psicología Médica y Social (5th ed.). Barcelona: Salvat.

Buston, K., Parry-Jones, W., Livingstone, M., Bogan, A., \& Wood, S. (1998). Qualitative Research. British Journal of Psychiatry, 172, 197-199. http://dx.doi.org/10.1192/bjp.172.3.197

Cartwrigt, L. K. (1979). Sources and Effects of Stress in Health Careers. In G. C. En Stone, F. Cohe, \& N. E. Adlere (Eds.), Health Psychology. San Francisco: Jossey-Bass.

Cherniss, C. (1980). Staff Burnout. Job Stress in the Human Services. London: Sage Publications.

Dublin, L. I., \& Spiegelman, M. (1947). The Longevity and Mortality of American Physicians. JAMA, 134, 1211-1215. http://dx.doi.org/10.1001/jama.1947.02880320001001

Edewich, J., \& Brodsky, A. (1980). Burnout: Stages of Disillusionment in the Helping Professions. New York: Human Services Press.

Freudenberger, H. J. (1974). Staff Burnout. Journal of Social Issues, 30, 159-165. http://dx.doi.org/10.1111/j.1540-4560.1974.tb00706.x

García Arroyo, J. M. (2001a). Lo cuantitativo y lo cualitativo en Psicopatología: Una aproximación desde la subjetividad (Primera parte). Anales de Psiquiatria, 7, 319-324.

García Arroyo, J. M. (2001b). Lo cuantitativo y lo cualitativo en Psicopatología: Una aproximación desde la subjetividad (Segunda parte). Anales de Psiquiatria, 7, 325-332.

García Arroyo, J. M. (2004). El "binarismo subjetivo”: Sus determinantes y sus implicaciones sobre el "autoconcepto” y la "autoestima”. Anales de Psiquiatria, 20, 252-261.

García Arroyo, J. M. (2007). Es posible cuantificar la subjetividad? In Interpsiquis (Revista electrónica de psiquiatría).

García Arroyo, J. M., \& Domínguez López, M. L. (2010). Por dónde seguir investigando en psicopatología? Informaciones Psiquiátricas, 199, 39-56.

King, H. (1970). Health in the Medical and Other Learned Professions. Journal of Chronic Diseases, 23, $275-281$.

Krakowski, A. J. (1982). Stress and the Practice of Medicine-The Myth and Reality. Journal of Psychosomatic Research, 26, 91-98. http://dx.doi.org/10.1016/0022-3999(82)90068-X

Marmor, J. (1953). The Feeling of Superiority. American Journal of Psychiatry, 110, 370-376.

Maslach, C. (1979). The Burnout Syndrome and Patients Care. In C. A. Garfield (Ed.), Stress and Survival: The Emotional Realities of Life-Threatening Illness (pp. 111-120). St Louis, MO: Mosby.

Maslach, C., \& Jackson, S. (1981). The Measurement of Experienced Burnout. Journal of Organizational Behavior, 2, 99113. http://dx.doi.org/10.1002/job.4030020205

Maslach, C., \& Jackson, S. (1982). Burnout in Health Professions: A Social Psychological Analysis. In G. S. Sanders, \& J. Suls (Eds.), Social Psychology of Health and Illness (pp. 227-251). Hillsdale, NJ: Lawrence Erlbaum.

Mingote Adán, J. C., \& Pérez Corral, F. (1999). El estrés del médico. Madrid: Diaz de Santos.

Moreno, B., Oliver, C., Pastor, J. C., \& Aragoneses, A. (1990). El burnout, una forma especifica de estrés laboral. In V. E. Caballo, \& G. Buela (Comp.), Manual de Psicología Clínica Aplicada. Madrid: Siglo XXI.

Munarriz, M. (2004). Métodos cualitativos. In J. Vallejo, \& C. Leal (Eds.), Tratado de Psiquiatría (Vol. 1). Barcelona: Ars 
Médica.

Rodríguez Marín, J. (2001). Psicología Social y de la Salud. Madrid: Síntesis.

Rojo Sierra, M. (1980). Psicología y psicopatología de la percepción, memoria y fantasía. El bloque informativo de la persona humana. Barcelona: Eunibar.

Taylor, S., \& Bogdan, R. (1992). Introducción a los métodos cualitativos de investigación. Barcelona: Paidós.

Vaillant, G. E., Sobowale, N., \& McArthur, Ch. (1972). Some Psychological Vulnerabilities of Physicians. New England Journal of Medicine, 287, 372-375. http://dx.doi.org/10.1056/NEJM197208242870802

Vaillant, G. E. (1977). Adaptation to Life. Boston, MA: Little Brown and Co.

Vega, E. D., \& Pérez Urdaniz, A. (1998). El síndrome burnout en el médico. Madrid: Smith Kline Beecham. 
Scientific Research Publishing (SCIRP) is one of the largest Open Access journal publishers. It is currently publishing more than 200 open access, online, peer-reviewed journals covering a wide range of academic disciplines. SCIRP serves the worldwide academic communities and contributes to the progress and application of science with its publication.

Other selected journals from SCIRP are listed as below. Submit your manuscript to us via either submit@scirp.org or Online Submission Portal.
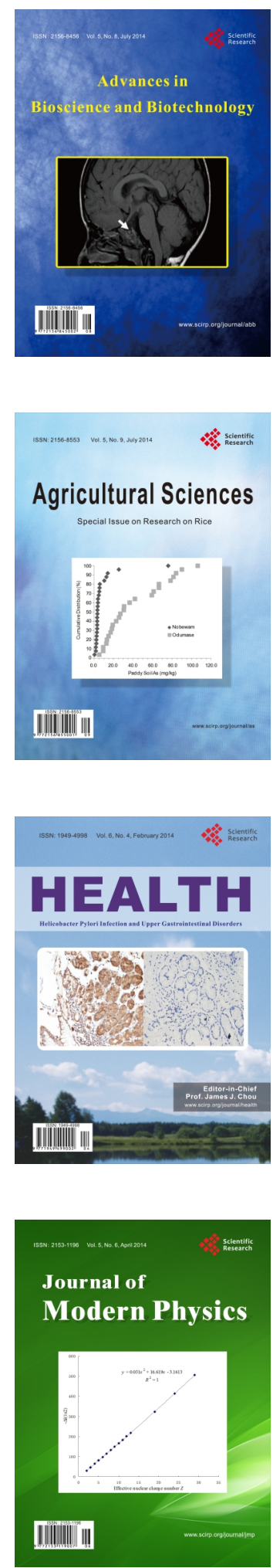
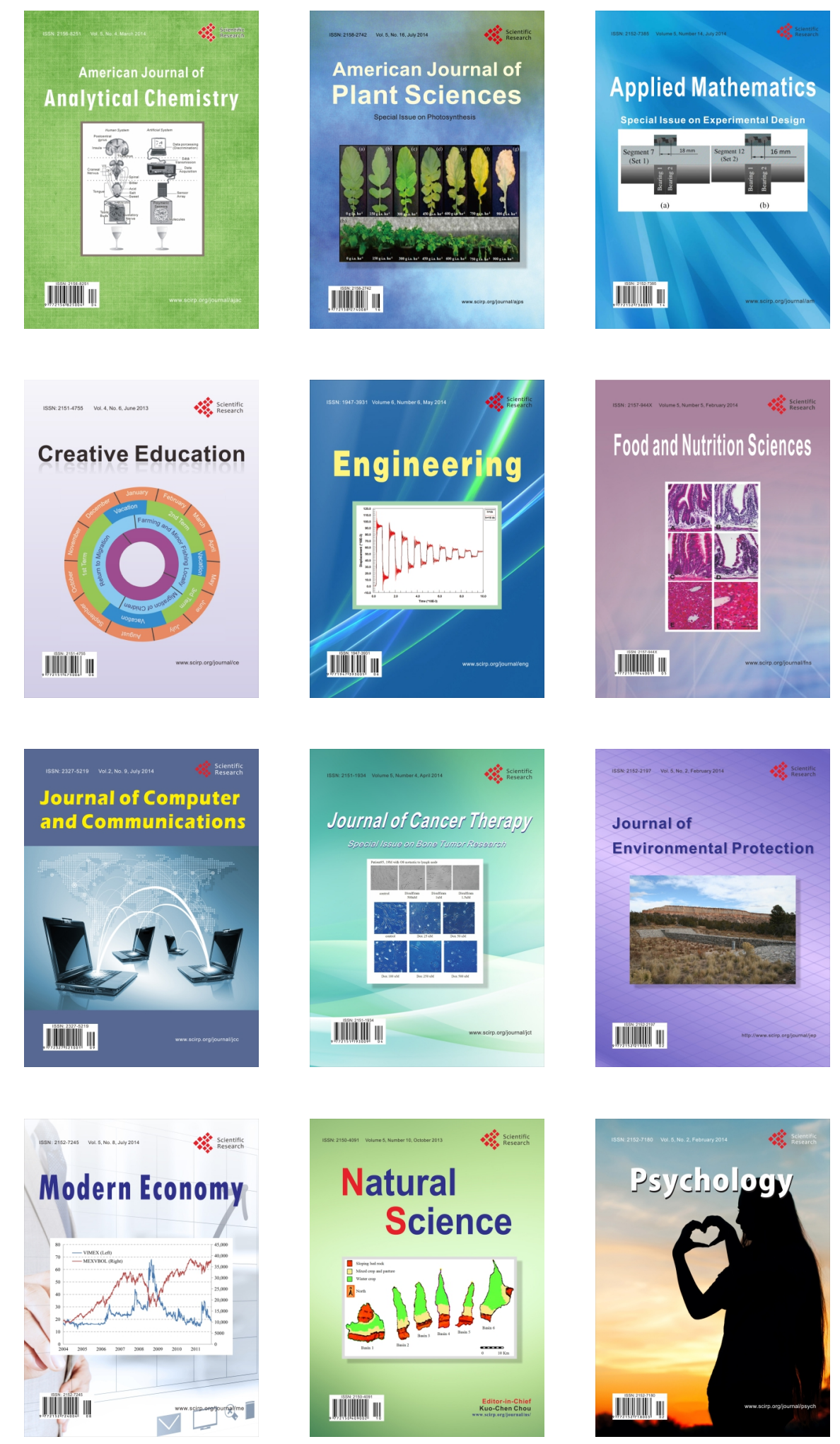